Revised

\title{
Ultrasonographic reproductive tract measures and pelvis measures as predictors of pregnancy failure and anestrus in restricted bred beef heifers
}

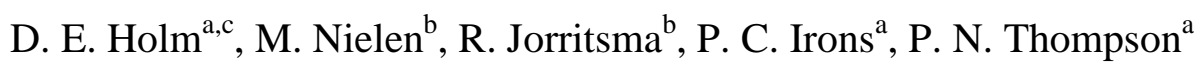

\author{
${ }^{a}$ Department of Production Animal Studies, Faculty of Veterinary Science, University of Pretoria, Private \\ Bag X04, Onderstepoort, 0110, South Africa \\ ${ }^{\mathrm{b}}$ Department of Farm Animal Health, Faculty of Veterinary Medicine, Utrecht University, Yalelaan 7, 3584 \\ CL, Utrecht, Netherlands
}

${ }^{\mathrm{c} C}$ Corresponding author: dietmar.holm@up.ac.za; Telephone: +27125298000

\begin{abstract}
Previous reports have shown that reproductive tract score (RTS) can predict reproduction outcomes in seasonally bred beef heifers, although the accuracy can vary. Some ultrasonographic measures of the female reproductive tract and pelvis area have also been associated with reproductive outcome in young heifers. The objectives of this study were to determine which transrectal ultrasound or pelvis measures taken at a single examination are independent predictors of reproductive failure, and if the RTS system can be optimised with this information. In this observational study 488 year-old beef heifers in 2 birth cohorts were followed from prior to first breeding until confirmation of pregnancy. A single pre-breeding examination included BCS, RTS, ultrasound measures
\end{abstract}


of the reproductive tract (length and diameter of the left and right ovaries, presence and diameter of a CL, largest follicle diameter and left uterus horn diameter) and transverse and vertical diameters of the pelvis. Additional farm records including dam parity, sire, birth weight and birth date, weaning weight, weaning date, pre-breeding BW, AI dates and semen used were available. Breeding consisted of $50 \mathrm{~d}$ of AI, followed 5 to $7 \mathrm{~d}$ later by a $42 \mathrm{~d}$ bull breeding period. Pregnancy failure was defined as the failure to become pregnant after the AI and bull breeding periods while anestrus was defined as the failure to be detected in estrus during the $50 \mathrm{~d}$ AI period. From the pre-breeding data and farm records independent predictors of pregnancy failure and anestrus were identified using step-wise reduction in multiple logistic regression models. Age at the onset of breeding was the only consistent independent predictor of pregnancy failure and anestrus in both cohorts of this study $(P<0.05)$. BCS, uterus horn diameter, absence of a CL, largest follicle of less than $13 \mathrm{~mm}$ and pelvis area (PA) were the pre-breeding examination variables that remained in prognostic models $(P<0.1)$. Combining either the model based on the three remaining ultrasound measures or RTS with PA provided more accurate prognostic models for pregnancy failure and anestrus than using RTS alone $(P<$ 0.05). It is concluded that ultrasound measures have prognostic value for pregnancy failure in restricted bred yearling heifers as a result of their association with anestrus, and that smaller pelvis area has additional prognostic value for poor performing heifers.

\section{Keywords}

beef cattle

fertility

heifer selection 
pelvis area

reproductive tract score

ultrasonography

\section{INTRODUCTION}

The ability to select young heifers that will reproduce effectively in a seasonal breeding system has advantages over the alternative approach of waiting until reproductive failure occurs $[1,2]$. Reproductive tract score (RTS) predicts anestrus and pregnancy failure in heifers independently of age, body weight (BW) and body condition score (BCS), and is a valid selection tool to enhance reproductive performance of herds [3-7]. However, estrus cycle stage and proportion of heifers in anestrus affect the accuracy of RTS, the complexity of the RTS system affects its repeatability, and other tests with potential to improve RTS are available [5,7-9].

The ultrasonographic presence of a corpus luteum (CL) has been used to mark the onset of puberty, has substantial repeatability, is more accurate than blood progesterone determination and is a predictor of reproductive outcome in seasonally bred cows and heifers [9-12]. Ovary size is associated with antral follicle count (AFC), which in turn is associated with follicular reserve and fertility, whereas AFC is not affected by estrus cycle stage $[13,14]$. Maximum follicle diameter is correlated with uterus, cervix and vaginal diameter, and increases in the 10 weeks prior to first ovulation in heifers, due to increased LH pulse frequency [13,15-19]. Larger pelvis area has been associated with early onset of puberty in heifers and improved libido in bulls [20-22].

The objective of this study was to determine which individual transrectal ultrasound or pelvis measures taken at one point in time before breeding are independent 
predictors of reproductive failure in seasonally bred beef heifers, and whether this knowledge can be used to optimise RTS.

\section{MATERIALS AND METHODS}

This was an observational study of 488 uniquely identified Bovelder beef heifers born in either $2007(n=259)$ or $2008(n=229)$ (2007 and 2008 cohorts) that were followed from just prior to their first breeding season to confirmation of pregnancy. The farming system, breed and location have been described previously [5,7,20,23-25]. Farm data collected included the following: birth weight and birth date, parity of dam, sire, bull allocated and first to fourth AI day numbered from the mating start date (MSD).

Heifers were weighed either 22 d (2007 cohort) or 27 or 24 d (2008 cohort) before the MSD (pre-breeding BW), and a single pre-breeding examination was performed $7 \mathrm{~d}$ (2007 cohort) or 27 or 24 d (2008 cohort) before the MSD. During the pre-breeding examination heifers were restrained individually in a chute, and the following data were collected in the same order by one experienced veterinarian: Firstly BCS was determined using a 9-point scale [26]. This was followed by RTS by trans-rectal palpation using a 5point scale [3], then followed by trans-rectal ultrasonographic measurements of the reproductive tract [27], using a real-time digital ultrasound imaging system set in B-mode with a variable frequency linear probe set at $5 \mathrm{MHz}$ (SIUI CTS-900V, Shantou Institute of Ultrasonic Instruments, Shantou, China). The interpolar length of the left and right ovaries, the diameter of the left and right ovaries at the deepest point (2008 cohort only), the presence and diameter of a CL, the diameter of the largest follicle and diameter of the left uterus horn near the base (UD) were recorded. Finally internal vertical diameter (VD) and transverse diameter (TD) of the pelvis were measured by transrectal placement of a 
caliper type pelvimeter (Rice pelvimeter, Lane Manufacturing, Denver, Colorado) $[20,28,29]$. Farm management and staff were blinded to all the measured pre-breeding data throughout the trial, except for the pre-breeding BW.

The MSD was October 15 of each year and breeding consisted of $50 \mathrm{~d}$ of continuous estrus observation by visual inspection, and once daily AI of all heifers identified in estrus during the preceding $24 \mathrm{~h}$ by the same inseminator. Five to $7 \mathrm{~d}$ after each 50-day AI season all heifers were joined with bulls in a single multisire group at a heifer:bull ratio of 30-35:1 for 42 days. Pregnancy diagnoses were performed by transrectal palpation 138 d or 165 d after MSD (2007 and 2008 cohorts respectively).

For the purpose of regression models, BCS was categorised into 2 categories $(<6$ and $\geq 6$ ) and RTS into 3 categories (1-2, 3 and 4-5) [30]. Diameter of the largest follicle was used either as a continuous variable or was dichotomized using various cut-offs $(7,8$, 9, 12, 13 and $14 \mathrm{~mm}$ ). Pelvis area (PA) was calculated as the product of the TD and VD, and rescaled values of PA (RPA) as well as uterus diameter (RUD) were calculated within birth cohort using the following formula:

$$
\begin{gathered}
\mathrm{x}^{*}=\left(\mathrm{x}-\mathrm{x}_{\text {minimum }}\right) \div\left(\mathrm{x}_{\text {maximum }}-\mathrm{x}_{\text {minimum }}\right) \\
\text { where } \mathrm{x}^{*}=\text { either RPA or RUD, and } \\
\mathrm{x}=\mathrm{PA} \text { or UD }
\end{gathered}
$$

If a heifer was not detected in estrus it was assumed that she remained prepubertal until the end of the 50-day AI season, and was defined as anestrus, whereas pregnancy failure was defined as a negative pregnancy test at the end of the AI and bull breeding periods. 
Correlations were estimated using Spearman's correlation for non-normally distributed data (only age in this study) and Pearson's correlation for normally distributed data. Independent proportions were compared using the Fisher exact test and means and medians were compared using ANOVA with the Tukey-Kramer multiple comparison test and Kruskal-Wallis one-way ANOVA, respectively.

Multiple linear regression models (for length of the longest ovary, diameter of the largest follicle, UD and PA) and logistic regression models (for absence of a CL, absence of a follicle $\geq 13 \mathrm{~mm}$, anestrus and pregnancy failure) were constructed using a backward elimination process [31] with $P<0.20$ for initial inclusion and $P_{\text {Wald }}<0.10$ for retention in models. Predictors that were considered included year of birth, dam parity $(1,2$ or $\geq 3)$, pre-breeding BW $(\mathrm{kg})$, growth rate $(\mathrm{kg} / \mathrm{d})$, age at onset of breeding $(\mathrm{d})$ and BCS category at examination, presence or diameter $(\mathrm{mm})$ of the $\mathrm{CL}$, diameter $(\mathrm{mm})$ of the largest follicle or presence of a follicle of at least 7, 8, 9, 12, 13 or $14 \mathrm{~mm}, \mathrm{RUD}, \mathrm{RPA}$ and length of the longest or shortest ovary ( $\mathrm{mm})$, or combined length of the two ovaries $(\mathrm{mm})$, or ovary length difference $(\mathrm{mm})$. Once only independent variables remained in each model $\left(P_{\text {Wald }}<0.10\right)$, each of the eliminated variables was included individually again to test for confounding. Confounding was considered if inclusion of a variable changed the coefficient of one of the independent predictors by more than $15 \%$.

Finally, independent pre-breeding examination predictors of anestrus and pregnancy failure were combined into different prognostic models in order to estimate which models provided the best predictions of the outcomes. Areas under the receiver operating characteristic (ROC) curves (ROC-AUC) of prognostic models for anestrus and pregnancy failure were compared using the algorithm of DeLong et al. [32]. 
Data analysis was done using NCSS 2007 (NCSS, Kaysville, UT, USA) and STATA 11.1 (StataCorp, Texas, USA).

Table 1. Pre-breeding measures and reproductive outcomes per year of birth and per sampling day.

\begin{tabular}{|c|c|c|c|}
\hline & \multicolumn{3}{|c|}{ Sampling day } \\
\hline & \multirow{2}{*}{$\begin{array}{c}\text { d }-7 \\
(n=259) \\
\text { Born 2007 }\end{array}$} & $\begin{array}{c}\mathbf{d}-27 \\
(\mathbf{n}=\mathbf{1 3 4})\end{array}$ & $\begin{array}{c}d-24 \\
(n=95)\end{array}$ \\
\hline & & \multicolumn{2}{|c|}{ Born $2008(n=229)$} \\
\hline Age at examination $(d)^{1}$ & $401 \pm 31^{\mathrm{a}}[311-449]$ & \multicolumn{2}{|c|}{$383 \pm 27^{\mathrm{b}}[308-453]$} \\
\hline Age at the onset of breeding $(d)^{1}$ & $407 \pm 31^{\mathrm{a}}[317-455]$ & \multicolumn{2}{|c|}{$408 \pm 27^{\mathrm{a}}[331-479]$} \\
\hline Pre-breeding BW (kg) ${ }^{1}$ & $292 \pm 36^{\mathrm{a}}[195-392]$ & \multicolumn{2}{|c|}{$272 \pm 34^{\mathrm{b}}[184-349]$} \\
\hline Vertical pelvis diameter $(\mathrm{cm})^{1}$ & $12.9 \pm 0.9^{\mathrm{a}}[11-16]$ & \multicolumn{2}{|c|}{$12.6 \pm 1.1^{\mathrm{b}}[8-15]$} \\
\hline Transverse pelvis diameter $(\mathrm{cm})^{1}$ & $11.0 \pm 0.9^{\mathrm{a}}[8.5-13]$ & \multicolumn{2}{|c|}{$10.6 \pm 1.0^{\mathrm{b}}[8-13]$} \\
\hline Largest follicle diameter $(\mathrm{mm})^{1}$ & $10.7 \pm 2.8^{\mathrm{a}}[4-18]$ & \multicolumn{2}{|c|}{$11.1 \pm 2.4^{\mathrm{a}}[4-17]$} \\
\hline Proportion with $\mathbf{C L}$ & $101 / 259(39 \%)^{\mathrm{a}}$ & \multicolumn{2}{|c|}{$56 / 229(24 \%)^{\mathrm{b}}$} \\
\hline CL diameter $(\mathbf{m m})^{1}$ & $21.9 \pm 4.5^{\mathrm{a}}[11-30]$ & \multicolumn{2}{|c|}{$20.7 \pm 4.4^{\mathrm{a}}[11-30]$} \\
\hline Left ovary interpolar length $(\mathrm{mm})^{1}$ & $24.3 \pm 5.7^{\mathrm{a}}[13-43]$ & \multicolumn{2}{|c|}{$23.1 \pm 4.7^{\mathrm{b}}[12-36]$} \\
\hline Left ovary diameter $(\mathbf{m m})^{1}$ & $\mathrm{~N} / \mathrm{D}^{2}$ & \multicolumn{2}{|c|}{$14.0 \pm 4.2[5-40]$} \\
\hline Right ovary interpolar length $(\mathrm{mm})^{1}$ & $25.8 \pm 5.6^{\mathrm{a}}[13-42]$ & $24.1 \pm 5.1^{\mathrm{b}}[14-43]$ & $26.5 \pm 6.0^{\mathrm{a}}[11-42]$ \\
\hline Right ovary diameter (mm) ${ }^{1}$ & $\mathrm{~N} / \mathrm{D}$ & $14.0 \pm 4.2^{\mathrm{a}}[8-30]$ & $15.1 \pm 4.1^{\mathrm{b}}[8-29]$ \\
\hline Left uterus horn diameter $(\mathrm{mm})^{1}$ & $15.3 \pm 2.6^{\mathrm{a}}[10-24]$ & $12.2 \pm 1.9^{\mathrm{b}}[7-17]$ & $11.7 \pm 1.5^{\mathrm{c}}[8-15]$ \\
\hline Proportion with pregnancy failure & $56 / 258(22 \%)^{\mathrm{a}}$ & \multicolumn{2}{|c|}{$38 / 219(17 \%)^{\mathrm{a}}$} \\
\hline Proportion with anestrus & $51 / 259(20 \%)^{\mathrm{a}}$ & \multicolumn{2}{|c|}{$50 / 229(22 \%)^{\mathrm{a}}$} \\
\hline
\end{tabular}

${ }^{1}$ Mean \pm SD [minimum and maximum]

${ }^{\mathrm{a}, \mathrm{b}, \mathrm{c}}$ Means or proportions in rows with differing superscripts differ significantly $(P<0.05)$.

${ }^{2}$ Not done

\section{RESULTS}

The age (mean $\pm \mathrm{SD})$ of heifers at pre-breeding weighing $(384 \pm 28.8 \mathrm{~d})$ and at the onset of breeding $(407 \pm 28.7 \mathrm{~d})$ were similar for the 2 birth cohorts $(P=0.74$ and $P=0.27$ 
respectively), but heifers born in 2007 were examined at an older age than those born in $2008(P<0.01$, Table 1$)$. Heifers born in 2007 were significantly heavier pre-breeding than those born in $2008(P<0.01$, Table 1$)$ and BCS (median, interquartile range (IQR)) was also higher in the 2007 cohort $(6,5-6$ and 5, 5-6 respectively, $P<0.01)$. More heifers were in RTS categories 4 or 5 (247/488) compared to categories 1 or $2(102 / 488)$ and RTS $3(139 / 488)(P<0.01)$, and the proportions were similar between birth cohorts $(P=$ 0.87). Pelvis and ultrasound measures of the reproductive tract are reported in Table 1. The UD differed between the two birth cohorts (Table 1). Further, in the 2008 cohort sampling day was associated with right ovary length and diameter, and with UD $(P<$ 0.05, Table 1). The left ovaries had shorter mean interpolar length than that of the right (23.7 and $25.5 \mathrm{~mm}$ respectively, $P<0.01$ ), but the mean diameter of the left and right ovaries for heifers born in 2008 did not differ (14.0 and $14.4 \mathrm{~mm}$ respectively, $P=0.26$ ).

Age, BCS, length of the longest ovary, diameter of the CL and UD at the time of examination, and pre-breeding BW were all positively correlated with each other $(P<$ 0.05). The diameter of the largest follicle was positively correlated with the length of the longest ovary and the length of the shortest ovary $(P<0.05)$. Reproductive tract score was most markedly associated with the length of the longest ovary, the length of the shortest ovary and the absence of a CL (Table 2). It was also associated with the diameter of the CL and the diameter of the largest follicle, less so with UD and the absence of a follicle $\geq 8 \mathrm{~mm}$ but not associated with the absence of a follicle $\geq 13 \mathrm{~mm}$ (Table 2). 
Table 2. Different ultrasonographic measures of the reproductive tract per reproductive tract score (RTS) category.

\begin{tabular}{|c|c|c|c|c|c|}
\hline Ultrasound variable & $\begin{array}{c}\text { RTS 1 } \\
(n=15)\end{array}$ & $\begin{array}{c}\text { RTS 2 } \\
(\mathbf{n}=\mathbf{8 7})\end{array}$ & $\begin{array}{c}\text { RTS 3 } \\
(n=139) \\
\end{array}$ & $\begin{array}{c}\text { RTS } 4 \\
(n=120)\end{array}$ & $\begin{array}{c}\text { RTS 5 } \\
(n=127)\end{array}$ \\
\hline Longest ovary length $(\mathbf{m m})^{1}$ & $20.7 \pm 4.3^{\mathrm{a}}$ & $23.0 \pm 3.0^{\mathrm{b}}$ & $25.6 \pm 3.2^{c}$ & $28.4 \pm 3.5^{\mathrm{d}}$ & $33.0 \pm 4.5^{\mathrm{e}}$ \\
\hline Shortest ovary length $(\mathbf{m m})^{1}$ & $16.8 \pm 2.9^{\mathrm{a}}$ & $19.1 \pm 2.6^{\mathrm{b}}$ & $21.3 \pm 3.2^{c}$ & $22.8 \pm 3.6^{\mathrm{d}}$ & $23.0 \pm 4.0^{\mathrm{d}}$ \\
\hline Absence of a CL ${ }^{2}$ & $\begin{array}{c}15 / 15 \\
(100 \%)^{\mathrm{a}, \mathrm{b}}\end{array}$ & $\begin{array}{c}87 / 87 \\
(100 \%)^{\mathrm{a}}\end{array}$ & $\begin{array}{l}127 / 138 \\
(92 \%)^{b}\end{array}$ & $\begin{array}{l}82 / 120 \\
(68 \%)^{c}\end{array}$ & $\begin{array}{l}19 / 127 \\
(15 \%)^{\mathrm{d}}\end{array}$ \\
\hline CL diameter $(\mathbf{m m})^{1}$ & - & - & $18.0 \pm 4.7^{\mathrm{a}}$ & $18.9 \pm 3.9^{\mathrm{a}}$ & $22.7 \pm 4.1^{b}$ \\
\hline Largest follicle diameter & $5 / 15$ & $12 / 87$ & $16 / 138$ & $8 / 120$ & $12 / 127$ \\
\hline$<8 \mathrm{~mm}^{2}$ & $(33 \%)^{\mathrm{a}}$ & $(14 \%)^{\mathrm{a}, \mathrm{b}}$ & $(12 \%)^{b}$ & $(7 \%)^{\mathrm{b}}$ & $(9 \%)^{b}$ \\
\hline Largest follicle diameter & $14 / 15$ & $69 / 87$ & $105 / 138$ & $82 / 120$ & $93 / 127$ \\
\hline$<13 \mathrm{~mm}^{2}$ & $(93 \%)^{\mathrm{a}}$ & $(79 \%)^{\mathrm{a}}$ & $(76 \%)^{\mathrm{a}}$ & $(68 \%)^{\mathrm{a}}$ & $(73 \%)^{\mathrm{a}}$ \\
\hline $\begin{array}{l}\text { Largest follicle diameter } \\
(\mathrm{mm})^{1}\end{array}$ & $8.7 \pm 3.3^{\mathrm{a}}$ & $10.4 \pm 2.5^{b}$ & $10.7 \pm 2.5^{\mathrm{b}}$ & $11.4 \pm 2.5^{\mathrm{c}}$ & $11.1 \pm 2.7^{\mathrm{b}, \mathrm{c}}$ \\
\hline $\begin{array}{l}\text { Uterus horn diameter } \\
(\mathbf{m m})^{1}\end{array}$ & $12.7 \pm 3.0^{\mathrm{a}}$ & $13.4 \pm 2.6^{\mathrm{a}}$ & $13.6 \pm 2.9^{\mathrm{a}}$ & $14.0 \pm 2.9^{\mathrm{a}, \mathrm{b}}$ & $14.2 \pm 2.6^{\mathrm{b}}$ \\
\hline
\end{tabular}

In the multi-variable models, weaning weight and age at examination were independently associated with presence of a CL, whereas only pre-breeding BW was independently associated with presence of a follicle $\geq 13 \mathrm{~mm}$ (Table 3). Pre-breeding BW, age at examination and presence of a CL were independently associated with UD, and age at examination, presence of a CL and largest follicle diameter were independently associated with the length of the longest ovary (Table 3). Dam parity 1 (vs $>1$ ), weaning weight, pre-breeding BW, age at examination, BCS and presence of a CL were all independently associated with PA (Table 3). 
Table 3. Summary of the multiple logistic- or linear regression models of selected pre-breeding measures.

\begin{tabular}{|c|c|c|c|c|c|}
\hline \multirow[b]{2}{*}{ Predictor } & \multicolumn{5}{|c|}{ Multi-variable model outcome } \\
\hline & $\begin{array}{l}\text { Presence of } \\
\qquad a \mathbf{C L}^{1}\end{array}$ & $\begin{array}{l}\text { Largest } \\
\text { follicle } \geq \\
13 \mathrm{~mm}^{1}\end{array}$ & $\begin{array}{c}\text { Uterus } \\
\text { diameter } \\
(\mathbf{m m})^{2}\end{array}$ & $\begin{array}{c}\text { Longest } \\
\text { ovary } \\
\text { length } \\
(\mathbf{m m})^{2}\end{array}$ & $\begin{array}{c}\text { Pelvis area } \\
\qquad\left(\mathrm{cm}^{2}\right)^{2}\end{array}$ \\
\hline Dam parity >1 (vs 1) & \# & $\#$ & \# & $\#$ & $\begin{array}{c}-4.15(-7.63, \\
-0.66)\end{array}$ \\
\hline $\begin{array}{l}\text { Wean weight } \\
\text { (10 kg units) }\end{array}$ & $\begin{array}{c}1.16(1.08, \\
1.25)\end{array}$ & $\#$ & \# & \# & $\begin{array}{c}0.89(0.05 \\
1.74)\end{array}$ \\
\hline $\begin{array}{l}\text { Pre-breeding BW } \\
\text { (10 kg units) }\end{array}$ & \# & $\begin{array}{c}1.08(1.02, \\
1.14)\end{array}$ & $\begin{array}{c}0.06(-0.01 \\
0.13)\end{array}$ & \# & $\begin{array}{c}2.35(1.61 \\
3.09)\end{array}$ \\
\hline $\begin{array}{l}\text { Age at examination } \\
\text { (w) }\end{array}$ & $\begin{array}{c}1.13(1.06, \\
1.20)\end{array}$ & $\#$ & $\begin{array}{c}0.07(0.01 \\
0.12)\end{array}$ & $\begin{array}{c}0.09(0.00, \\
0.18)\end{array}$ & $\begin{array}{c}0.58(0.16 \\
1.00)\end{array}$ \\
\hline $\begin{array}{l}\text { BCS at examination } \\
\geq 6\end{array}$ & \# & \# & \# & \# & $\begin{array}{c}-3.25(-5.92 \\
-0.59)\end{array}$ \\
\hline Presence of a CL & $\mathrm{N} / \mathrm{a}$ & $\mathrm{N} / \mathrm{a}$ & $\begin{array}{c}0.58(0.14 \\
1.01)\end{array}$ & $\begin{array}{c}6.38(5.56, \\
7.21)\end{array}$ & $\begin{array}{c}7.64(5.00 \\
10.30)\end{array}$ \\
\hline $\begin{array}{l}\text { Largest follicle } \\
\text { diameter (mm) }\end{array}$ & $\mathrm{N} / \mathrm{a}$ & $\mathrm{N} / \mathrm{a}$ & \# & $\begin{array}{c}0.31(0.16 \\
0.45)\end{array}$ & \# \\
\hline Year of birth 2007 & $\begin{array}{c}1.55(1.00, \\
2.40)\end{array}$ & $\#$ & $\begin{array}{c}3.13(2.72, \\
3.55)\end{array}$ & \# & $\begin{array}{c}3.68(0.78 \\
6.59)\end{array}$ \\
\hline
\end{tabular}

${ }^{1}$ Odds ratios $(95 \%$ C.I.) of independent predictors $(P<0.10)$ in logistic regression models

${ }^{2}$ Regression coefficients (95\% C.I.) of independent predictors $(P<0.10)$ in multiple regression models

N/a: Not analysed

\#Not an independent predictor $(P>0.10)$

Body condition score, absence of a CL, largest follicle $<13 \mathrm{~mm}$, RUD and RPA were the pre-breeding examination variables that remained in multivariable models of 
Table 4: Summary of logistic regression models for pregnancy failure and anestrus in the two birth cohorts combined.

\begin{tabular}{lcc}
\hline Independent predictor & Outcome: pregnancy failure & Outcome: $^{\mathbf{1}}$ \\
\hline CL absent & $1.69(0.94,3.05)$ & $6.13(2.32,16.21)$ \\
Largest follicle $<\mathbf{1 3} \mathbf{~ m m}$ & $2.07(1.10,3.90)$ & $2.13(1.09,4.16)$ \\
Rescaled uterus diameter & $0.43(0.18,1.02)$ & $0.39(0.15,1.01)$ \\
Rescaled pelvis area & $\#$ & $0.15(0.05,0.48)$ \\
Age at onset of breeding (w) & $0.88(0.83,0.93)$ & $0.90(0.84,0.96)$ \\
BCS <6 & $\#$ & $2.90(1.66,5.08)$
\end{tabular}

${ }^{1}$ Odds ratios (95\% C.I.) of independent predictors $(P<0.10)$

\#Not an independent predictor $(P>0.10)$

Table 5. Logistic regression model for prediction of anestrus using independent transrectal ultrasound measures of the reproductive tract in combination with pelvis area $(n=488)^{1}$.

\begin{tabular}{|c|c|c|c|c|c|}
\hline \multirow{2}{*}{$\begin{array}{l}\text { Predictor } \\
\text { Constant }\end{array}$} & \multirow{2}{*}{$\begin{array}{c}\text { Coefficient } \\
-2.13\end{array}$} & \multirow{2}{*}{$\begin{array}{c}\mathbf{O R}^{2} \\
0.12\end{array}$} & \multicolumn{2}{|c|}{$95 \% \mathrm{CI}$} & \multirow{2}{*}{$\begin{array}{c}\boldsymbol{P} \\
<0.01\end{array}$} \\
\hline & & & 0.03 & 0.41 & \\
\hline CL absent & 1.97 & 7.15 & 2.75 & 18.57 & $<0.01$ \\
\hline $\begin{array}{l}\text { Largest follicle } \\
<13 \mathrm{~mm}\end{array}$ & 0.81 & 2.25 & 1.19 & 4.27 & 0.01 \\
\hline $\begin{array}{l}\text { Rescaled uterus } \\
\text { diameter }\end{array}$ & -0.96 & 0.38 & 0.16 & 0.94 & 0.04 \\
\hline $\begin{array}{l}\text { Rescaled pelvis } \\
\text { area }\end{array}$ & -2.77 & 0.06 & 0.02 & 0.18 & $<0.01$ \\
\hline
\end{tabular}

pregnancy failure and anestrus $(P<0.1$, Table 4$)$. The prognostic model for anestrus 
using the three remaining pre-breeding ultrasonographic measures of the reproductive tract in combination with RPA (US + RPA model) yielded an ROC-AUC of 0.81 (Table 5, Figure 1). The US + RPA model, and the model combining RTS with RPA (RTS + RPA model) provided more accurate predictions of pregnancy failure and anestrus than using RTS alone $(P<0.05$, Table 6). The RPA model and the model using ultrasonographic absence of a CL, absence of a follicle $\geq 13 \mathrm{~mm}$ and RUD (US model) tended to predict anestrus better than RTS ( $P=0.09$ and $P=0.06$ respectively). The RPA model tended to predict pregnancy failure better than RTS $(P=0.09)$.

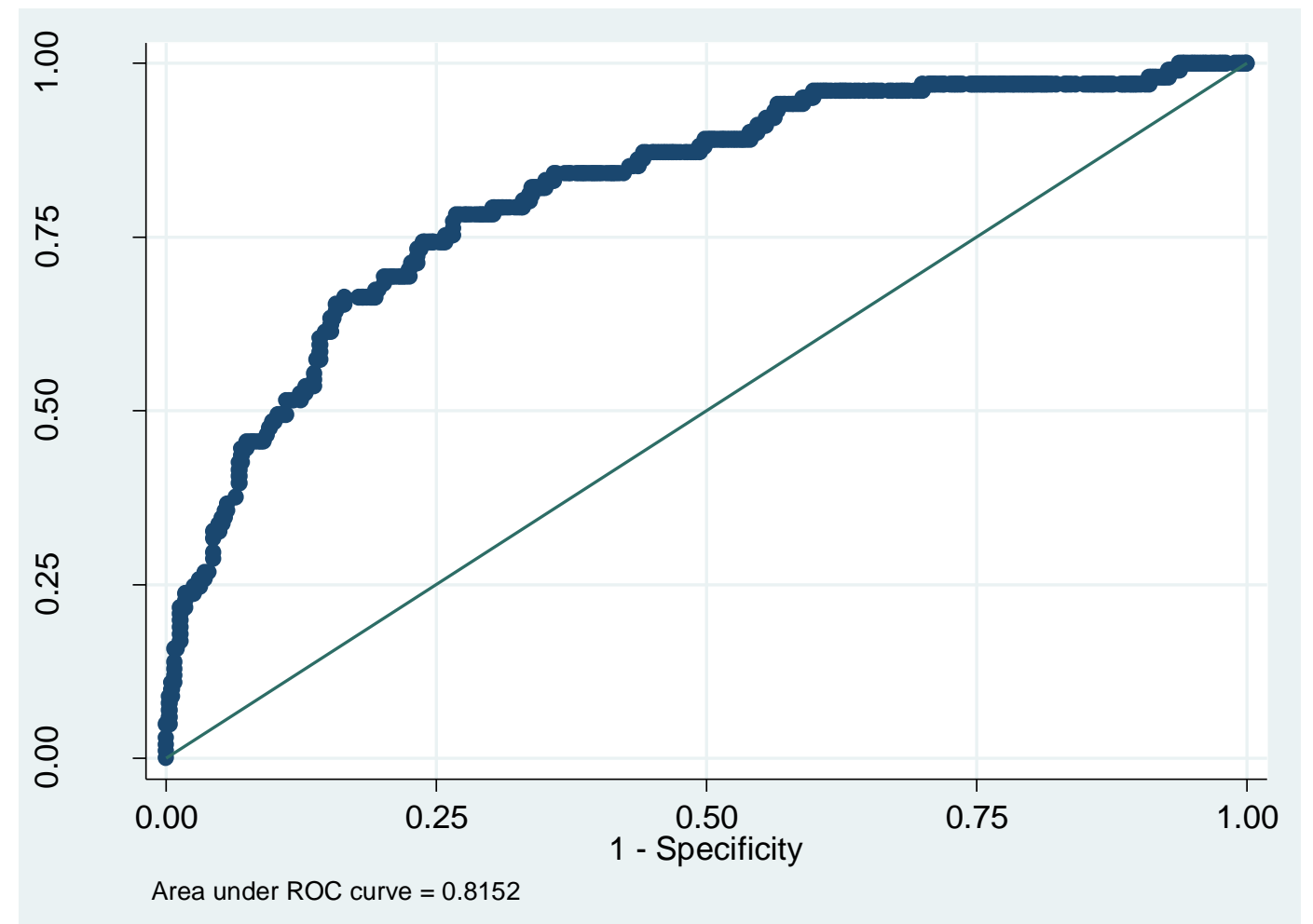

Figure 1: Receiver operating characteristic (ROC) curve for anestrus using the model based on the ultrasonographic absence of a CL, absence of a follicle $\geq 13 \mathrm{~mm}$, rescaled uterus diameter and rescaled pelvis area (Table 5). 
Table 6: Areas under the receiver operating characteristic curves (ROC-AUC) of different predictive models for pregnancy failure and anestrus in the two birth cohorts separately and combined.

\begin{tabular}{lcccccc}
\hline & \multicolumn{3}{c}{ Pregnancy failure } & \multicolumn{3}{c}{ Anestrus } \\
Model & $\mathbf{2 0 0 7}$ & $\mathbf{2 0 0 8}$ & Combined & $\mathbf{2 0 0 7}$ & $\mathbf{2 0 0 8}$ & Combined \\
& cohort & cohort & data & cohort & cohort & data \\
\hline RTS $^{1}$ & $0.59^{\mathrm{a}}$ & $0.63^{\mathrm{a}}$ & $0.60^{\mathrm{a}}$ & $0.72^{\mathrm{a}}$ & $0.69^{\mathrm{a}}$ & $0.71^{\mathrm{a}}$ \\
RPA $^{2}$ & $0.62^{\mathrm{a}, \mathrm{b}}$ & $0.63^{\mathrm{a}}$ & $0.62^{\mathrm{a}}$ & $0.74^{\mathrm{a}, \mathrm{b}}$ & $0.78^{\mathrm{b}}$ & $0.76^{\mathrm{a}}$ \\
Ultrasound $^{3}$ & $0.70^{\mathrm{b}, \mathrm{c}}$ & $0.64^{\mathrm{a}}$ & $0.65^{\mathrm{a}, \mathrm{b}}$ & $0.77^{\mathrm{a}, \mathrm{b}, \mathrm{c}}$ & $0.76^{\mathrm{a}, \mathrm{b}}$ & $0.76^{\mathrm{a}, \mathrm{b}}$ \\
RTS + RPA & $0.63^{\mathrm{a}, \mathrm{b}}$ & $0.65^{\mathrm{a}}$ & $0.64^{\mathrm{a}, \mathrm{b}}$ & $0.79^{\mathrm{b}, \mathrm{c}}$ & $0.80^{\mathrm{b}, \mathrm{c}}$ & $0.79^{\mathrm{b}, \mathrm{c}}$ \\
Ultrasound + RPA & $0.71^{\mathrm{c}}$ & $0.67^{\mathrm{a}}$ & $0.68^{\mathrm{b}}$ & $0.81^{\mathrm{c}}$ & $0.83^{\mathrm{c}}$ & $0.81^{\mathrm{c}}$ \\
\hline
\end{tabular}

${ }^{1}$ RTS categorized as 1-2, 3, 4-5, with 4-5 as reference value

${ }^{2}$ Rescaled pelvis area

${ }^{3}$ Ultrasonographic absence of a CL, absence of a follicle $\geq 13 \mathrm{~mm}$ and rescaled uterus diameter

${ }^{\mathrm{a}, \mathrm{b}, \mathrm{c}}$ ROC-AUC values in columns with differing superscripts differ significantly $(P<0.05)$

\section{DISCUSSION}

In this study ultrasonographic measures of the reproductive tract, and pelvis measures were compared as pre-breeding predictors of pregnancy failure and anestrus in seasonally bred beef heifers, and this information was used to determine if the current RTS system can be optimised.

Despite good heritability of age at puberty (AP) $[11,33]\left(\mathrm{h}^{2}=0.52\right.$ and 0.43 respectively), environmental factors from fetal development to puberty can influence the phenotypic expression of reproductive potential $[5,11,19]$, which may have led to different levels of pubertal development achieved by the MSD in the two birth cohorts in this study. However the anestrus- and pregnancy failure proportions were not different 
and we assumed that considering year of birth as a potential covariate in models would adequately adjust for any differences between the years.

The difference in UD between the two birth cohorts in this study may have occurred as a result of a true biological difference in the younger group of heifers in 2008 [19], or may have been a systematic measuring error that occurred during sampling [34]. The relatively small UD reported in the 2008 cohort of the present study compared to the 2007 cohort as well as previous reports $[3,19]$ indicates that a systematic error was more likely to have occurred in the 2008 cohort than in the 2007 cohort. The possibility of such an error to occur justifies the use of a rescaled value of the raw data in analyses, and we assumed that the relative uterus diameter within birth cohort in the present study, rather than the absolute diameter provided a better indication of the relative pubertal development stage of an animal within a group. We assumed the same for PA data.

The difference in length between the left and right ovaries could either have been a true biological difference [35], or it could also have been a systematic measuring error due to the operator using the same hand, and the alignment of the ultrasound probe being different on the left and right ovaries [27]. Honaramooz et al. [19] could not demonstrate a difference in ultrasonographic size between the left and right ovaries, however the largest follicle on the right side was $1 \mathrm{~mm}$ larger than on the left side in their data. The fact that there was a numerical difference in ovary diameter between the two sides in the 2008 cohort, that was not significant, is not useful to support either of the two hypotheses. It may be that an adjustment for the side of the largest ovary may improve the ability of the length of the longest ovary to predict reproductive outcomes, but due to 
obvious confounding by the size of the largest follicle and the presence of a CL on the predictive ability of ovary length, this was not investigated any further.

Age at examination was associated with UD and PA independent of BW, confirming that the development of the reproductive system is a function of both age and $\mathrm{BW}$, and that age and BW when puberty is reached varies between animals, even in a uniform group such as the study population [5]. The age range of the study population fell in or just after the second phase of rapid development of the reproductive tract $[15,19]$, and as such a lot of variance could be expected due to the proximity to puberty. The results of this study may therefore not necessarily be extrapolated to heifers in other age ranges.

\subsection{Individual independent predictors of reproductive outcomes}

None of the ovary length variables were independently associated with reproductive outcomes in this study. However, two significantly independent predictors of reproductive outcomes, largest follicle $\geq 13 \mathrm{~mm}$ and the presence of a CL at the time of examination, were both also independent predictors of ovary length, and we conclude that the effect of ovary length on reproductive outcome is confounded by the presence of ovarian structures. Cushman et al. [13] and Ireland et al. [14] suggested that the size of the ovaries may give a reflection of antral follicle count, which is associated with fertility in young adult cattle. Antral follicle count was not considered as an input variable in the current study, however we assumed that either longest-, shortest- or combined ovary length would provide a reflection of antral follicle count after adjustment for the size of the largest follicle and the size or presence of a CL. 
The diameter of the largest follicle was not correlated with UD as was the case in the study of Honaramooz et al. [19], and was only independently associated with the length of the longest ovary, both which appear in this study to be confounded in their prognostic value for reproductive outcomes. After testing several cut-off points to dichotomise the diameter of the largest follicle, $<13 \mathrm{~mm}$ was the only predictor of anestrus and pregnancy failure in this study, which is in agreement with the observation by Honaramooz et al. [19] that the maximum follicle size increases prior to puberty from 10 to $12 \mathrm{~mm}$. We conclude that heifers in the current trial that did not have a CL, and also had a largest follicle diameter $<13 \mathrm{~mm}$ were at risk of being too far from puberty at the time of examination to show estrus during the 50-day AI season, or to become pregnant during the breeding season. None of the other follicle size cut-offs tested had any significant associations in this study, indicating that whether dominance of a follicle has occurred, or not (using a cut-off between 7 and $9 \mathrm{~mm}$ [36]) did not have prognostic value for reproductive outcome in our study.

Previous findings indicating the superior ability of ultrasonography to detect the presence of a CL [10] are supported by this study due to the fact that significant proportions of heifers with ultrasonographically visible CLs were assigned RTS 3 or 4 . These CLs were smaller than those of heifers with RTS 5, and were most likely not easily palpable, however the tendency of the ultrasound model to have a better predictive value for anestrus and pregnancy failure when compared to RTS is likely partly as a result of the better sensitivity of ultrasound to detect a CL. In the current study the absence of a CL not only predicted anestrus, but also pregnancy failure. Keeping in mind that the total breeding season length was 90 days, this can be partly explained by the fact that the first 
few ovulations after puberty have lower fertility than later ovulations $[37,38]$, which will further decrease the ability of heifers that reach puberty after the MSD to become pregnant during a restricted breeding season.

Although not validated against estrus or pregnancy outcomes during the breeding period following examination, Archbold et al. [6] estimated the sensitivity of ultrasonography to determine pubertal status to be reduced during pro-estrus and metestrus, due to the relatively poor ability to visualise the regressing corpus albicans and the corpus haemoragicum respectively. We therefore assume that the reason why the absence of a follicle $\geq 13 \mathrm{~mm}$ remained an independent predictor in our models was either that some heifers that were pubertal at the time of examination had their first estrus in the few days after the examination, or that in postpubertal heifers a CL was not detected due to stage of the estrus cycle. Due to the fact that some heifers may have been at stages of the follicular wave before divergence of the dominant follicle at the time of examination [36] the absence of a follicle $\geq 13 \mathrm{~mm}$ cannot completely rule out cyclicity, but improves the predictive ability when a CL is not present.

\subsection{Optimising the RTS system for improved accuracy}

Due to the inaccuracy of transrectal palpation relative to ultrasonography to detect a CL, to distinguish between follicles $<13 \mathrm{~mm}$ and $\geq 13 \mathrm{~mm}$ and to estimate the uterus horn diameter, transrectal ultrasonography tended to provide better prognostic models for reproductive failure than the current palpation model of Andersen et al. [3]. However the accuracy of RTS by palpation may be improved by putting more emphasis on the presence of a CL, the size of the largest follicle and the diameter of the uterus horn, and less emphasis on the absolute size of the two ovaries. Our data confirms that the operator 
assigning the RTS scores weighed the size of the ovaries relatively heavily in the scoring system, but this study further indicated that the size of the ovaries after adjusting for ultrasonographically visible structures on the ovaries was not an independent predictor of reproductive outcome, and should preferably not be emphasised.

Pelvis area, a measure previously used only to predict dystocia in heifers [28,29], had a strong and independent association with reproductive outcome in this study, and added significant prognostic value to models based on palpation or ultrasonography of the reproductive tract. This is in agreement with previous reports of associations between PA and reproductive outcomes $[21,22]$. Similar to uterus diameter, pelvis area has the potential to overcome the inaccuracy to predict pubertal stage at a single point in time caused by different stages of the estrus cycle. We assume that the reason why pelvis area predicted reproductive outcome independent of other measures, and why it added significant prognostic value to models predicting reproductive failure, is because it develops gradually over time and is probably not significantly associated with the daily estrus cycle stage.

The absence of a CL, being the best predictor of reproductive failure, was a particularly good predictor in the 2007 birth cohort, in which case heifers were examined closer to the MSD, and the proportion of heifers with a CL was also higher. In the 2008 cohort, when heifers were examined more than $3 \mathrm{w}$ before the MSD, BCS, uterus diameter and PA were more important predictors of anestrus and pregnancy failure. We suggest that emphasis should be placed on different predictors depending on the age of heifers at the time of examination, or depending on the proportion of heifers with CLs at the time of examination. When heifers are examined long before the MSD, or when only 
a small proportion of heifers have CLs, more emphasis should be placed on the relative diameter of the uterus horn and the relative PA, whereas when examination is done shortly before the MSD, or when a larger proportion of heifers have CLs, more emphasis should be placed on the absence of a CL and the absence of a follicle $\geq 13 \mathrm{~mm}$ diameter. Further research is needed, possibly using Bayesian modelling, to establish if different prognostic models should be applied based on herd status.

\section{CONCLUSIONS}

Transrectal ultrasonography of the reproductive tracts of beef heifers can provide prognostic models of pregnancy failure due to its association with anestrus during a restricted breeding season. The ultrasonographic measures that remained independent predictors of pregnancy failure and anestrus were the absence of a CL, absence of a follicle $\geq 13 \mathrm{~mm}$, and relatively smaller uterus horn diameter.

Relatively smaller pelvis area (PA) can either replace, or add value to reproductive tract scoring by transrectal palpation or ultrasonography as predictor of poor reproductive performance in restricted bred beef heifers.

\section{ACKNOWLEDGEMENTS}

The authors thank Roger and Lynette Wood of Johannesburg Water's Northern Farm for providing the animals, facilities and farm data, and Reinette van Reenen and Daleen Anderson for assistance with data capture. This research was performed under protocol no V089/13, as approved by the Animal Ethics Committee of the University of Pretoria.

Conflicts of interest: None 


\section{References}

[1] Chenoweth PJ. Cow/calf production principles. In: Chenoweth PJ, Sanderson MW, editors. Beef practice; Cow-calf production medicine, Ames, Iowa: Blackwell Publishing; 2005, p. 9-28.

[2] Cushman RA, Kill LK, Funston RN, Mousel EM, Perry GA. Heifers calving date positively influences calf weaning weights through six parturitions. J Anim Sci 2013;91:4486-91.

[3] Andersen KJ, LeFever DG, Brinks JS, Odde KG. The use of reproductive tract scoring in beef heifers. Agri-Practice 1991;12(4):19-26.

[4] Pence M., Ensley D, Berghaus R, Rossi J, Wilson T, Cannon PT. Improving Reproductive Efficiency Through the Use of Reproductive Tract Scoring in a Group of Beef Replacement Heifers. Bov Prac 2007;41(1):35-40.

[5] Holm DE, Thompson PN, Irons PC. The value of reproductive tract scoring as a predictor of fertility and production outcomes in beef heifers. J Anim Sci 2009;87:193440.

[6] Archbold H, Shalloo L, Kennedy E, Pierce KM, Buckley F. Influence of age, body weight and body condition score before mating start date on the pubertal rate of maiden Holstein-Friesian heifers and implications for subsequent cow performance and profitability. Animal 2012;6(7):1143-51.

[7] Holm DE, Nielen M, Jorritsma R, Irons PC, Thompson PN. Evaluation of prebreeding reproductive tract scoring as a predictor of long term reproductive performance of beef heifers. Prev Vet Med 2015;118:56-63. 
[8] Rosenkrans KS, Hardin DK. Repeatability and accuracy of reproductive tract scoring to determine pubertal status in beef heifers. Theriogenology 2003;59(5-6):1087-92. [9] Archbold H, Buckley F, Pierce KM, Begley N, Mee JF. Ultrasonography and progesterone concentration at a single time point for the detection of puberty in dairy heifers. Reprod Domest Anim 2012; 47:407-11.

[10] Lean IJ, Abe N, Duggan S, Kingsford N. 1992. Within and between observer agreement on ultrasonic evaluation of bovine ovarian structures. Aust Vet J 1992;69:27982.

[11] Johnston DJ, Barwick SA, Corbet NJ, Fordyce G, Holroyd RG, Williams PJ et al. Genetics of heifer puberty in two tropical beef genotypes in northern Australia and associations with heifer- and steer-production traits. Anim Prod Sci 2009;49:399-412. [12] Mee JF, Buckley F, Ryan D, Dillon P. Pre-breeding ovaro-uterine ultrasonography and its relationship with first service pregnancy rate in seasonal calving dairy herds. Reprod Domest Anim 2009;44:331-7.

[13] Cushman RA, Allan MF, Kuehn LA, Snelling WM, Cupp AS, Freetly HC.

Evaluation of antral follicle count and ovarian morphology in crossbred beef cows: Investigation of influence of stage of the estrous cycle, age, and birth weight. J Anim Sci 2009;87:1971-80.

[14] Ireland JJ, Smith GW, Scheetz D, Jimenez-Krassel F, Folger JK, Ireland JLH et al. Does size matter in females? An overview of the impact of the high variation in the ovarion reserve on ovarian function and fertility, utility of anti-Müllerian hormone as a diagnostic marker for fertility and causes of variation in the ovarian reserve in cattle. Reprod Fertil Dev 2011;23:1-14. 
[15] Desjardin C, Hafs HD. Maturation of bovine female genitalia from birth through puberty. J Anim Sci 1969;28:502-7.

[16] Day ML, Imakawa K, Garcia-Winder M, Zalesky DD, Schanbacher BD, Kittok RJ et al. Endocrine mechanisms of puberty in heifers: Estradiol negative feedback regulation of luteinizing hormone secretion. Biol Reprod 1984;31:332-41.

[17] Day ML, Imakawa K, Wolfe PL, Kittok RJ, Kinder JE. Endocrine mechanisms of puberty in heifers. Role of hypothalamo- pituitary estradiol receptors in the negative feedback of estradiol on luteinizing hormone secretion. Biol Reprod 1987;37:1054-65. [18] Bergfelt EGM, Kojima FN, Cupp AS, Wehrman ME, Peters KE, Garcia-Winder M et al. Ovarian follicular development in prepubertal heifers is influenced by level of dietary energy intake. Biol Reprod 1994;51:1046-50.

[19] Honaramooz A, Aravindakshan J, Chandolia RK, Beard AP, Bartlewski PM, Pierson RA et al. Ultrasonographic evaluation of the pre-pubertal development of the reproductive tract in beef heifers. Anim Reprod Sci 2004;80:15-29.

[20] Holm DE, Webb EC, Thompson PN. A new application of pelvis area data as culling tool to aid in the management of dystocia in heifers. J Anim Sci 2014;92:2296-303.

[21] Ramin AG, Daniel RCW, Fenwick DC, Verrall RG. Pelvic parameters, growth rate, puberty, and their interrelationships in young dairy heifers. Reprod Dom Anim 1995;30:117-23.

[22] Singh J, Kumar A, Dhaliwal GS. Pelvic area and scrotal circumference in relation to libido in breeding bulls. Indian Vet J 2010;87(4):396-7. 
[23] Paterson AG, Venter HAW, Harwin GO. Preweaning growth of British, Bos Indicus, Charolais and dual purpose type cattle under intensive pasture conditions. S Afr J Anim Sci 1980;10:125-34.

[24] Schoeman SJ, Jordaan GG. Animal x testing environment interaction on postweaning liveweight gains of young bulls. Aust J Agric Res 1998;49:607-12. [25] Holm DE, Thompson PN, Irons PC. The economic effects of an estrus synchronization protocol using prostaglandin in beef heifers. Theriogenology 2008;70:1507-15.

[26] Marston TT. Beef cowherd nutrition and management. In: Chenoweth PJ, Sanderson MW, editors. Beef practice; Cow-calf production medicine, Ames, Iowa: Blackwell Publishing; 2005, p. 89-108.

[27] DesCôteaux L, Gnemmi G, Colloton J. Ultrasonography of the bovine female genital tract. Vet Clin North Am Food Anim Pract 2009;25:733-52.

[28] Deutscher, G.H. 1988. Pelvis measurements: Key to reducing incidence of bovine dystocia. Norden News 63(2): 18-25.

[29] Van Donkersgoed, J. 1997. Pelvimetry In: Youngquist R. S. (ed) Current therapy in large animal theriogenology W.B.Saunders 306-9.

[30] Stevenson JL, Rodrigues JA, Braga FA, Bitente S, Dalton JC, Santos JEP et al. Effect of breeding protocols and reproductive tract score on reproductive performance of dairy heifers and economic outcome of breeding programs. J Dairy Sci 2008;91:3424-38. [31] Dohoo I, Martin W, Stryhn H. Veterinary epidemiologic research. Charlottetown, Canada: AVC Inc; 2003. 
[32] DeLong ER, DeLong DM, Clarke-Pearson DL. Comparing the areas under two or more correlated receiver operating curves: a nonparametric approach. Biometrics $1988 ; 44: 837-45$.

[33] Brinks JS. Genetic influences on reproductive performance of two-year-old beef females. In: Fields MJ, Sand RJ, editors. Factors Affecting Calf Crop. Boca Raton: CRC Press; 1994, p. 45-53.

[34] Melendez P, McHale J, Bartolome J, Archbald LF, Donovan GA. Uterine involution and fertility of Holstein cows subsequent to early postpartum $\mathrm{PGF}_{2 \alpha}$ treatment for acute puerperal metritis. J Dairy Sci 2004;87:3238-46.

[35] Petskol PG. Age and functional changes in mammalian ovaries. The age morphology of cattle ovaries (abstract). Trud Kirovsk zooteh -vet Inst 1941;4(16):49-74.

[36] Wiltbank MC, Gümen A, Sartori R. Physiological classification of anovulatory conditions in cattle. Theriogenology 2002;57:21-52.

[37] Byerley DJ, Staigmiller RB, Berardinelli JG, Short RE. Pregnancy rates of beef heifers bred either on puberal or third estrus. J Anim Sci 1987;65(3):645-50.

[38] Rawlings NC, Evans ACO, Honaramooz A, Bartlewski PM. Antral follicle growth and endocrine changes in prepubertal cattle, sheep and goats. Anim Reprod Sci 2003;78:259-270. 